\title{
Aberrant fibrillin-1 expression in early emphysematous human lung: a proposed predisposition for emphysema
}

\author{
Antoine A Robbesom ${ }^{1, *}$, Mieke MJF Koenders ${ }^{1, *}$, Nicole C Smits ${ }^{1}$, Theo Hafmans ${ }^{1}$, \\ Elly MM Versteeg ${ }^{1}$, Johan Bulten ${ }^{2}$, Jacques H Veerkamp ${ }^{1}$, PN Richard Dekhuijzen ${ }^{3}$ \\ and Toin $\mathrm{H}$ van Kuppevelt ${ }^{1}$
}

${ }^{1}$ Department of Biochemistry, Radboud University Nijmegen Medical Center, Nijmegen Center for Molecular Life Sciences, Nijmegen, The Netherlands; ${ }^{2}$ Department of Pathology, Radboud University Nijmegen Medical Center, Nijmegen, The Netherlands and ${ }^{3}$ Department of Pulmonary Diseases, Radboud University Nijmegen Medical Center, Nijmegen, The Netherlands

\begin{abstract}
Parenchymal destruction, airspace enlargement, and loss of elasticity are hallmarks of pulmonary emphysema. Although the basic mechanism is unknown, there is a consensus that malfunctioning of the extracellular matrix is a major contributor to the pathogenesis of emphysema. In this study, we analyzed the expression of the elastic fiber protein fibrillin-1 in a large number $(n=69)$ of human lung specimens with early-onset emphysema. Specimens were morphologically characterized by the Destructive Index, the Mean Linear Intercept, and the Panel Grading. We observed a strong correlation $(P<0.001)$ of aberrant fibrillin-1 staining with the degree of destruction of lung parenchyma $(r=0.71)$, airspace enlargement $(r=0.47)$, and emphysema-related morphological abnormalities $(r=0.69)$. There were no obvious correlations with age and smoking behavior. Staining for three other extracellular matrix components (type I collagen, type IV collagen, and laminin) was not affected. The aberrant fibrillin-1 staining observed in this study is similar to that observed in Marfan syndrome, a syndrome caused by mutations in the gene encoding fibrillin-1. Strikingly, emphysema is noticed in a number of Marfan patients. This, together with the notion that disruption of the fibrillin-1 gene in mice results in emphysematous lesions, makes fibrillin-1 a strong candidate to be involved in the etiology and pathogenesis of emphysema.
\end{abstract}

Modern Pathology (2008) 21, 297-307; doi:10.1038/modpathol.3801004; published online 14 December 2007

Keywords: pulmonary emphysema; lung; immunohistochemistry; fibrillin-1; elastic fiber; microfibril

Pulmonary emphysema is a progressive lung disease that is defined by an abnormal permanent enlargement of airspaces distal to the terminal bronchioles, accompanied by destruction of their walls and without obvious fibrosis. ${ }^{1}$ The prevailing theory is that emphysema develops through an imbalance between the proteolytic activity, due to proteases released from inflammatory cells, and the antiproteolytic defense of the lung. This protease/antiprotease imbalance results in the destruction of lung extracellular matrix and eventually leads to emphy-

Correspondence: Dr TH van Kuppevelt, PhD, Department of Biochemistry, Radboud University Nijmegen Medical Center, Nijmegen Center for Molecular Life Sciences, PO Box 9101, 6500 HB Nijmegen, The Netherlands.

E-mail: a.vankuppevelt@ncmls.ru.nl

* These authors contributed equally to this work.

Received 19 September 2007; revised and accepted 15 November 2007; published online 14 December 2007 sema. ${ }^{2}$ Another theory is the oxidant/anti-oxidant concept, which postulates that an excess of oxidants and free radicals in the lung directly promotes tissue damage and emphysema. ${ }^{3}$ Firm evidence for either of these concepts is lacking and consequently the pathogenesis of emphysema is still an area of intense investigation.

The pathogenesis of emphysema is characterized by the loss of elasticity. The network of elastic fibers is an important structural element in lung parenchyma and is, to a major extent, responsible for the elastic recoil properties of the lung. ${ }^{4,5}$ Elastic fibers are composed of 10-12 nm microfibrils located in and around amorphous elastin. ${ }^{6-8}$ Elastin, the major component of elastic fibers, has attracted much attention in emphysema research. However, evidence that associates elastin to the pathology of emphysema is lacking, although an amino-acid substitution in the elastin gene has been associated with chronic obstructive pulmonary diseases 
(COPDs), which include emphysema, in one family. ${ }^{9}$ Therefore, other molecules present in the elastic fiber may play important roles in the process of emphysema.

Fibrillin-1 is the major component of the microfibrillar part of the elastic fibers, although many other components, including fibulins, ${ }^{10-12}$ microfibril-associated glycoproteins, ${ }^{13-15}$ and emilins, ${ }^{16-18}$ are present. A number of observations have associated fibrillin-1 with developmental emphysema. In man, developmental emphysema has been noticed in patients with Marfan syndrome, an autosomal disorder caused by mutations in the gene encoding fibrillin-1. ${ }^{19-27}$ In mice, disruption of the fibrillin-1 gene results in developmental emphysema. The tight skin mouse, characterized by tandem duplication of $30-40 \mathrm{~kb}$ in the gene encoding fibrillin-1, develops emphysematous lesions that are in many ways similar to those observed in humans. ${ }^{28-32}$ In addition, mice harboring a targeted deletion of $6 \mathrm{~kb}$ of the fibrillin-1 gene also display emphysematous lesions. ${ }^{33}$ Both Marfan syndrome and the two mouse models share a mutated form of fibrillin-1 that gives rise to developmental emphysema. It is, however, unknown if fibrillin-1 also plays a role in the onset of adult emphysema.

This study reports on the role of fibrillin-1 in early-onset emphysema in adult humans. A major problem in the research into the onset of emphysema is the large time span between the initiation of the degenerative disease process and its clinical manifestations. At the time of clinical diagnosis, the process of parenchymal destruction is already in an advanced state, impeding the identification of initiating molecular events. Detailed morphological analysis of lung parenchyma allows for early identification of emphysema, especially since the definition of emphysema is based on morphological parameters. Therefore, we used lung specimens from patients without clinical emphysema but with microscopical emphysema, as defined by destruction of the alveolar wall and enlargement of the airspaces. ${ }^{34}$ On the basis of our data, a new concept for the onset of emphysema is proposed.

\section{Materials and methods}

\section{Lung Tissue}

Lung specimens were obtained from patients undergoing a lobectomy or pneumonectomy, for a localized malignant process, at the University Lung Center Nijmegen. All subjects were studied according to the guidelines of the Medical Ethical Committee of the Radboud University Nijmegen Medical Center. Specimens were sampled distantly from the tumor or in an unaffected lobe. Upon histological analysis, specimens did not show any sign of the underlying disease. Lung function tests were performed before surgery. Lung function data for all patients studied were within normal range, according to ERS standards. ${ }^{35}$

\section{Tissue Processing}

Small tissue specimens were taken from resected lung lobes. Each specimen was cut into pieces of equal size. One part was immersed in phosphatebuffered saline (PBS) and inflated under vacuum $(13 \mathrm{kPa})$ for $20 \mathrm{~min}$ using a routine water streamdriven device (water aspirator) to restore alveolar dimensions. ${ }^{36}$ This part was used for immunohistochemistry (see below). The other-adjacent-part was similarly inflated in PBS containing $4 \%$ formalin, embedded in paraffin, and used for morphological analysis (see below).

\section{Morphological Analysis}

Three morphological parameters were used to characterize human lung parenchyma and establish the severity of emphysema: the Destructive Index (DI, a measure for early parenchymal destruction), ${ }^{37}$ the Mean Linear Intercept (MLI, a measure for airspace enlargement), ${ }^{38}$ and Panel Grading (PG, morphological grading of emphysematous lesions). ${ }^{39}$ Hematoxylin and eosin (Sigma-Aldrich, St Louis, MO, USA)-stained sections ( $5 \mu \mathrm{m})$ were used.

\section{Destructive Index}

Using a microscopic point count technique, the DI was evaluated. Microscopic fields devoid of large bronchiole, large blood vessels, collapsed tissue, or extensive fibrosis were selected. For each lung specimen, an average of five different sections was used, and representative non-overlapping fields were selected. Alveoli lying underneath the counting points were evaluated for the presence of destruction. Destruction was defined on the basis of one or more of the following criteria: (a) at least two alveolar wall defects, (b) at least two intraluminal parenchymal rags in alveolar ducts, (c) clearly abnormal morphology, or (d) classic emphysematous changes. ${ }^{37}$ The percentage of all the points falling into these categories was computed to yield the DI. Generally, 750 points were analyzed per specimen with maxima up to 5000 points. A DI value of $0-30 \%$ was considered normal. ${ }^{37}$

\section{Mean Linear Intercept}

The MLI is a measure for airspace enlargement. To determine the MLI, the same images as described above were used. A transparent sheet with 10 horizontal and 11 vertical lines was laid over the images, and intercepts of alveolar walls with these lines were counted. Values were corrected for tissue shrinkage by measuring the dimensions before and after histological processing. The correction factor was 0.82 , which is in accordance with earlier 
studies. ${ }^{40}$ A total of 2500 intercepts were counted per specimen with maxima up to 18000 intercepts.

\section{Panel Grading}

The degree of emphysema in the images described above was analyzed by comparing the images with a panel of reference images. The grading ranged from 0 (normal tissue) to $100 \%$ (complete destruction). The PG value was expressed as an average percentage of severity of the lesions. The average number of measured slides per specimen was 6 .

\section{Study Group}

Sixty-nine lung parenchymal specimens, derived from patients without clinical emphysema, were selected on the basis of the three morphological parameters (DI, MLI, and PG). All of the 69 specimens studied were derived from patients with a history of smoking, ranging from 10 to 100 pack years. The characteristics of this study group are depicted in Table 1. Specimens originating from patients who had never smoked and had values within the normal range were used as a control $(n=7)$. Specimens originating from patients with other pulmonary diseases (large cell carcinoma $(n=2)$ and sarcoidosis $(n=2))$ were studied to evaluate the specificity of the data.

\section{Immunohistochemistry}

All incubations were performed at room temperature, unless stated otherwise. Cryosections of $2 \mu \mathrm{m}$ were cut and endogenous peroxidase was blocked with $0.3 \%(\mathrm{v} / \mathrm{v}) \mathrm{H}_{2} \mathrm{O}_{2}$ in PBS for $1 \mathrm{~h}$. Subsequently, sections were washed in PBS and incubated for $30 \mathrm{~min}$ with $1 \%(\mathrm{w} / \mathrm{v})$ bovine serum albumin (fraction V; Sigma-Aldrich) in PBS (block buffer).
Sections were incubated overnight with mouse antifibrillin-1 (mAb 1919, raised against bovine zonular fibrils; Chemicon International, Temecula, CA, USA) diluted 1:1000 in block buffer. After three washes in PBS, the primary antibody was detected with a biotinylated horse anti-mouse IgG antibody (Jackson Immuno Laboratories, West Grove, PA, USA) for $1 \mathrm{~h}$, followed by enhancement with the avidin-biotin-peroxidase complex (Vectastain ABC Elite kit; Vector Laboratories Inc., Burlingame, CA, USA) for $1.5 \mathrm{~h}$. After three washes in PBS, the sections were incubated with diaminobenzidine substrate (DAB) (Sigma-Aldrich), enhanced with nickel. After a final wash in PBS, the sections were counterstained with hematoxylin (Sigma-Aldrich) and mounted in entellan (Merck, Darmstadt, Germany).

Using the method described above, three other antibodies were used, namely, rabbit anti-laminin (L9393, 1:100 dilution; Sigma Immuno Chemicals, St Louis, MO, USA), a rabbit antibody against bovine type I collagen (1:100 dilution; Chemicon International), and a goat antibody against human type IV collagen (1340-01, 1:100 dilution; Southern Biotechnology Associates, Birmingham, AL, USA). Biotinylated donkey anti-rabbit IgG and donkey anti-goat IgG (Jackson Immuno Laboratories) were used to detect the primary antibodies.

All sections were randomly coded, and immunoreactivity was scored independently by two observers using a semiquantitative scale ranging from 0 (linear staining, no fragmentation) to 6 (punctuate staining, extensive fragmentation).

\section{Statistics}

Results were calculated with SPSS 11.0 (SPSS Inc., Chicago, IL, USA) using Spearman's two-sided ranked correlation and plotted in a scatter diagram.

Table 1 Characteristics of the study group and morphological data of the specimens studied

\begin{tabular}{|c|c|c|c|}
\hline & Normal $(\mathrm{n}=12)$ & $\begin{array}{l}\text { Moderate degree of microscopical } \\
\text { emphysema }(\mathrm{n}=27)\end{array}$ & $\begin{array}{l}\text { High degree of microscopical } \\
\text { emphysema }(\mathrm{n}=30)\end{array}$ \\
\hline \multicolumn{4}{|l|}{ Study group } \\
\hline Age (year) & $60 \pm 9$ & $61 \pm 8$ & $65 \pm 6$ \\
\hline Pack years & $29 \pm 9$ & $38 \pm 20$ & $39 \pm 21$ \\
\hline $\mathrm{FEV}_{1}$ (\% pred.) & $74 \pm 15$ & $82 \pm 19$ & $77 \pm 17$ \\
\hline $\mathrm{FEV}_{1} / \mathrm{VC}$ (\% pred.) & $82 \pm 1$ & $91 \pm 1$ & $78 \pm 2$ \\
\hline$K_{\text {co }}(\%$ pred. $)$ & $81 \pm 26$ & $82 \pm 22$ & $75 \pm 19$ \\
\hline TLC (\% pred.) & $93 \pm 23$ & $95 \pm 17$ & $102 \pm 13$ \\
\hline RV/TLC (\% pred.) & $105 \pm 21$ & $106 \pm 21$ & $108 \pm 18$ \\
\hline \multicolumn{4}{|c|}{ Morphological data specimens } \\
\hline DI $(\%)$ & $25 \pm 10$ & $58 \pm 8$ & $83 \pm 7$ \\
\hline $\operatorname{MLI}(\mu \mathrm{m})$ & $290 \pm 41$ & $319 \pm 43$ & $394 \pm 55$ \\
\hline PG (\%) & $31 \pm 11$ & $57 \pm 9$ & $78 \pm 8$ \\
\hline
\end{tabular}

DI, Destructive Index; MLI, Mean Linear Intercept; PG, Panel Grading; FEV , forced expiratory volume in 1 s; \% pred., percentage of predicted value; VC, vital capacity; $K_{\text {со }}$, diffusion capacity for CO; TLC, total lung capacity; RV, residual volume.

All values are means \pm s.d 


\section{Results}

\section{Study Group}

As depicted in Table 1, lung function of the 69 patients studied did not meet the GOLD (Global Initiative for Chronic Obstructive Lung Disease) criteria $^{41}$ for the diagnosis of emphysema. Sixtynine lung specimens were morphologically characterized for their degree of microscopical emphysema using the DI as a marker for early parenchymal destruction, the MLI as a marker for airspace enlargement, and the PG index as a value for emphysematous lesions. Three groups were formed: normal specimens, specimens with a moderate degree of microscopical emphysema, and specimens with a high degree of microscopical emphysema (Table 1).

\section{General}

To study fibrillin-1 expression, parenchymal lung specimens were stained with an antibody against fibrillin-1. In control specimens, fibrillin-1 was abundantly expressed in a characteristic fibrillar pattern (Figure 1a and b). Fibrillin-1 was identified in alveoli as elongated fibers meandering throughout the septa. No significant disruption of the linear fibrillin-1 staining was observed. In contrast, in specimens with a high degree of microscopical emphysema, the linear fibers were (almost completely) fragmented and had a punctuate appearance (Figure 2f).

Next to fibrillin-1, we studied other extracellular matrix components, namely, type IV collagen and laminin (both confined to basement membranes) and type I collagen. Type IV collagen and laminin showed a typical linear basement membrane staining (Figure 3d-f and g-i, respectively), whereas type I collagen was present as a typical fibrillar staining (Figure 3a-c). Staining for these extracellular matrix components did not reveal any differences in abundance or distribution for all specimens examined (Figure 3).

\section{Aberrant Fibrillin-1 Staining is Associated with Early Parenchymal Destruction}

The DI reflects the degree of parenchymal destruction and is considered the most sensitive marker for early emphysematous lesions. Lung specimens characterized by a low DI (normal lung specimens), indicating no parenchymal destruction, expressed fibrillin-1 abundantly (Figure 2d). This expression was comparable to the fibrillin-1 expression seen in control tissue (Figure 1). In lung specimens with moderate manifestations of parenchymal destruction (moderate degree of microscopical emphysema), fibrillin-1 expression was moderately disrupted and slightly reduced (Figure 2e). Lung specimens,
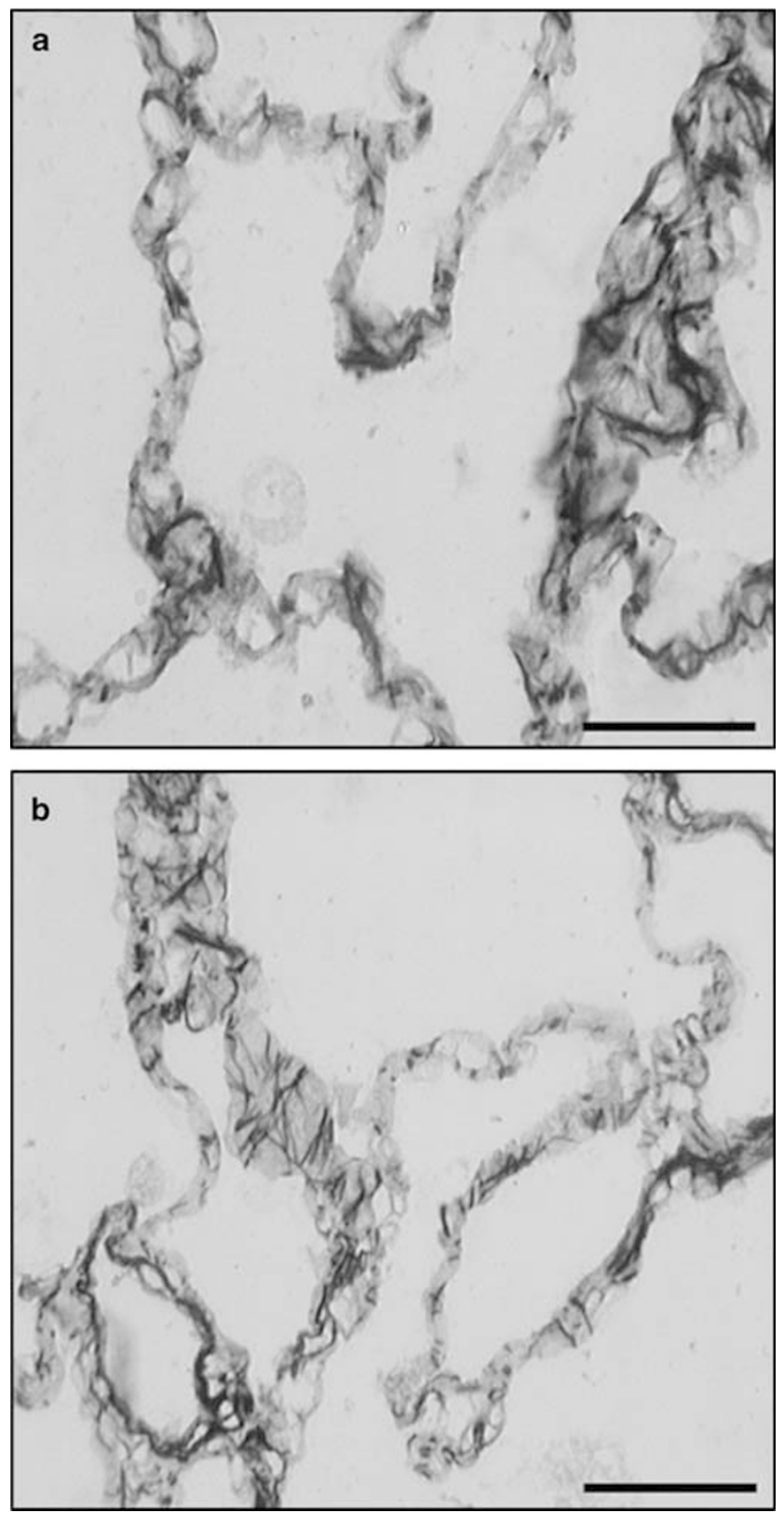

Figure 1 Fibrillin-1 immunostaining in normal human lung parenchyma. Two cryosections, derived from a 21-year-old patient who had never smoked and had no aberrant morphological parameters, were incubated with an antibody against fibrillin-1 (a, b). Bound antibody was visualized with biotinylated anti-mouse IgG followed by DAB incubation. Note the abundant fibrillar fibrillin-1 staining, which meandered throughout the alveolar septa. Bar $=50 \mu \mathrm{m}$.

characterized by severe manifestations of parenchymal destruction (high degree of microscopical emphysema), displayed a markedly reduced and fragmented fibrillin-1 staining, characterized by a punctuate appearance (Figure 2f). To semiquantify the degree of fragmentation, we used an arbitrary scale from 0 (no fragmentation) to 6 (complete fragmentation). When the degree of fibrillin-1 fragmentation was plotted against the degree of 

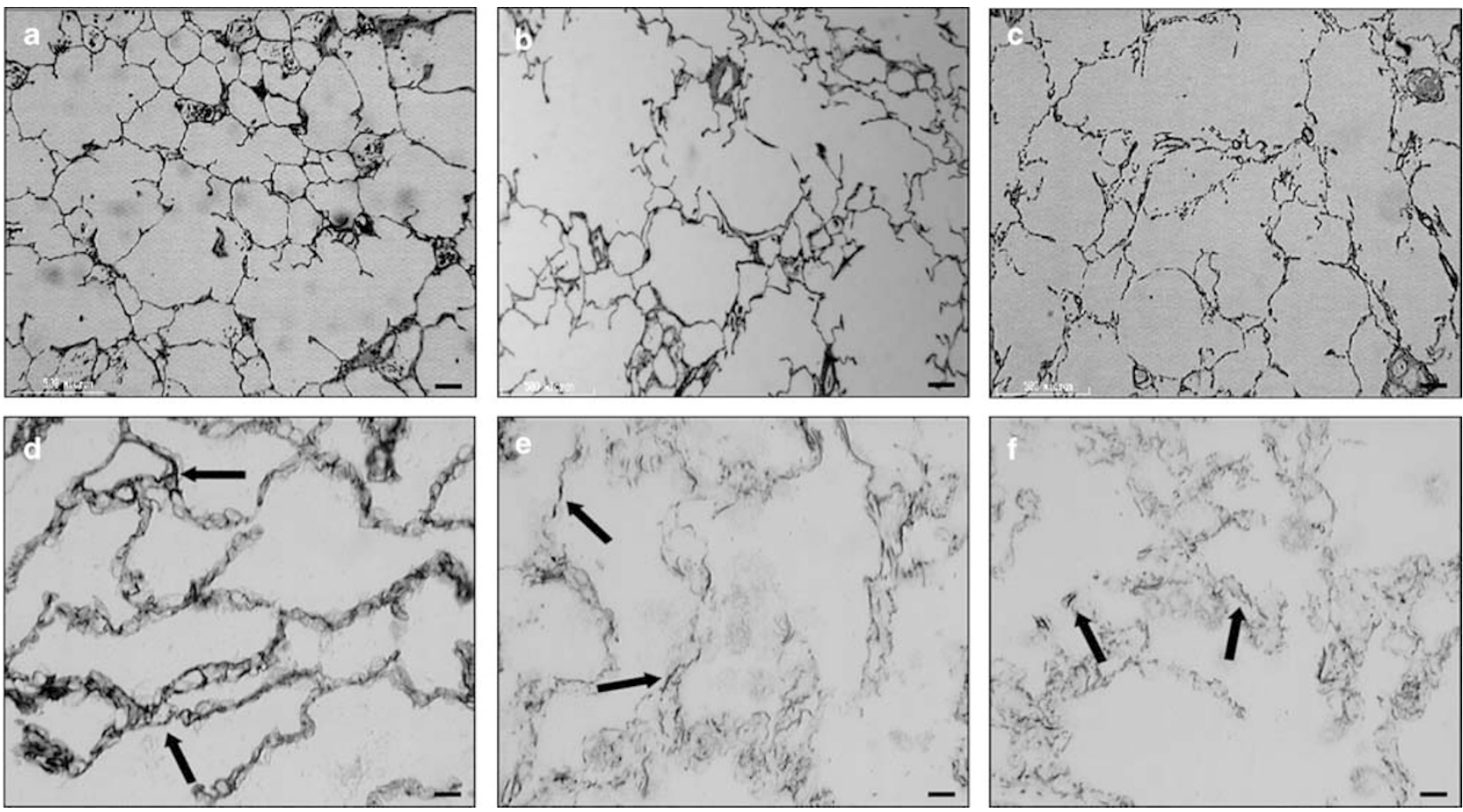

Figure 2 Fibrillin-1 immunostaining. Cryosections derived from a normal lung specimen (63 years, DI $=18 \%, \mathrm{MLI}=231 \mu \mathrm{m}, \mathrm{PG}=12 \%$ ) (a, d), a specimen with a moderate degree of microscopical emphysema (58 years, DI $=60 \%$, MLI $=273 \mu \mathrm{m}, \mathrm{PG}=52 \%)(\mathbf{b}$, e), and a specimen with a high degree of microscopical emphysema (68 years, DI $=87 \%$, MLI $=317 \mu \mathrm{m}, \mathrm{PG}=85 \%$ ) (c, f) were incubated with an antibody against fibrillin-1. Bound antibody was visualized with biotinylated anti-mouse IgG followed by DAB incubation. Note the parenchymal destruction and airspace enlargement in specimens with a moderate/high degree of microscopical emphysema (b, c). Compared to the lung specimens with no manifestations of alveolar destruction (d), where an abundant and branched fibrillin-1 staining was seen, a reduced fibrillin-1 staining was apparent in lung specimens with moderate manifestation of alveolar destruction (e). The staining showed fragmented fibers (arrows) instead of elongated fibers. In specimens with severe manifestations of alveolar destruction, fibrillin-1 staining was markedly reduced and had a dot-like or punctuate appearance (f, arrows). Bar $=50 \mu \mathrm{m}$.

parenchymal destruction, that is, the DI, a significant correlation $(P<0.001)$ was observed (Figure 4$)$.

\section{Aberrant Fibrillin-1 Staining is Associated with Airspace Enlargement and Emphysematous Abnormalities}

The MLI is a parameter for airspace enlargement. The presence of fragmented fibrillin-1 staining was plotted against the MLI (Figure 5), and a significant correlation $(P<0.001)$ was observed. The PG value reflects the overall degree of emphysematous abnormalities. A significant correlation $(P<0.001)$ was observed between the amount of fibrillin-1 fragmentation and PG (Figure 6).

\section{Aberrant Fibrillin-1 Staining is not Associated with Age}

The process of emphysema is age-dependent. Therefore, it may be assumed that the fibrillin-1 fragmentation is dependent on age. However, this appears not to be the case. When fibrillin-1 fragmentation was plotted against age (Figure 7a), no significant correlation was observed. Fibrillin-1 fragmentation was present at the same level in all age categories. For instance, staining derived in a specimen from a young individual (42 years) with a high DI $(70 \%)$ was highly fragmented, as was staining in a specimen from an older individual (68 years) with a high DI (87\%) (Figure 7c and e). Likewise, a young individual (41 years) with a low DI (11\%) displayed a normal fibrillin-1 staining, as did an older individual (78 years) with a low DI (23\%) (Figure $7 \mathrm{~b}$ and $\mathrm{d})$.

\section{Aberrant Fibrillin-1 Staining is not Associated with Smoking Behavior}

The degree of clinical emphysema is strongly correlated with smoking behavior. However, when fibrillin-1 fragmentation was plotted against smoking behavior, as expressed in pack years (one pack year is equal to smoking one pack of cigarettes per day during one year), no correlation was detected (Figure 8).

\section{Aberrant Fibrillin-1 Staining is not Associated with other Lung Diseases}

To evaluate the specificity of the aberrant fibrillin-1 staining for the process of emphysema, specimens derived from patients with other lung diseases (large cell carcinoma and sarcoidosis) were 

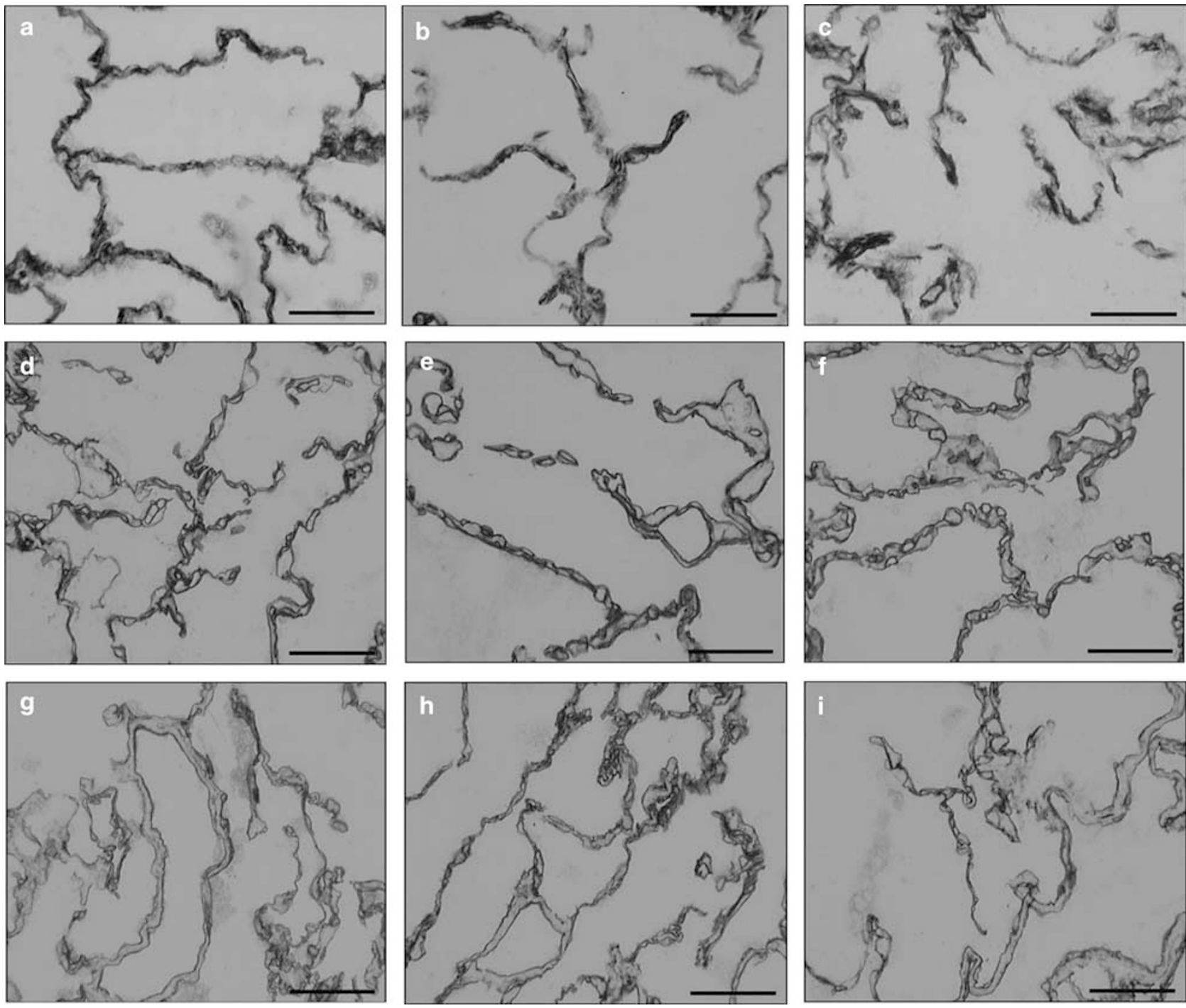

Figure 3 Type I collagen, type IV collagen, and laminin immunostaining. Cryosections derived from a normal lung specimen (63 years, $\mathrm{DI}=18 \%, \mathrm{MLI}=231 \mu \mathrm{m}, \mathrm{PG}=12 \%)(\mathbf{a}, \mathbf{d}, \mathbf{g})$, a specimen with a moderate degree of microscopical emphysema (58 years, DI $=60 \%$, $\mathrm{MLI}=273 \mu \mathrm{m}, \mathrm{PG}=52 \%)(\mathbf{b}, \mathbf{e}, \mathbf{h})$, and a specimen with a high degree of microscopical emphysema (68 years, DI $=87 \%, \mathrm{MLI}=317 \mu \mathrm{m}$, $\mathrm{PG}=85 \%)(\mathbf{c}, \mathbf{f}, \mathbf{i})$ were incubated with an antibody against type I collagen (a-c), type IV collagen (d-f), and laminin (g-i). Bound antibody was visualized with biotinylated IgG followed by DAB incubation. Note the fibrillar staining pattern for type I collagen and the liner basement membrane staining for type IV collagen and laminin. Type I collagen, type IV collagen, and laminin staining in specimens with a moderate or high degree of microscopical emphysema was similar to the staining in observed normal lung specimens. Bar $=50 \mu \mathrm{m}$.

immunostained for fibrillin-1 (Figure 9, for large cell carcinoma). Fibrillin-1 expression in these specimens was abundant with a striking absence of fibrillin-1 fragmentation, indicating the specificity of our observations.

\section{Discussion}

In this study, we showed that an aberrant fibrillin-1 staining in lung specimens was significantly associated with the three most important morphometric parameters for emphysema: the DI (alveolar destruction), the MLI (airspace enlargement), and the PG (emphysema-related morphological abnormalities).
Since emphysema is defined by an abnormal permanent enlargement of airspaces and by destruction of their walls, characterization of the disease with morphological parameters such as DI and MLI is a prerequisite to study the pathogenesis of emphysema. We collected lung specimens that had microscopical emphysema, as judged by morphometric analysis. ${ }^{34}$ Despite these morphological abnormalities, lung function tests were still within normal range, indicating that the process of lung destruction is still at an early stage. Lung function tests are a useful tool to diagnose COPD, a collective term including chronic bronchitis and emphysema. However, because lung function tests reflect airway obstruction and not loss of pulmonary parenchyma, 


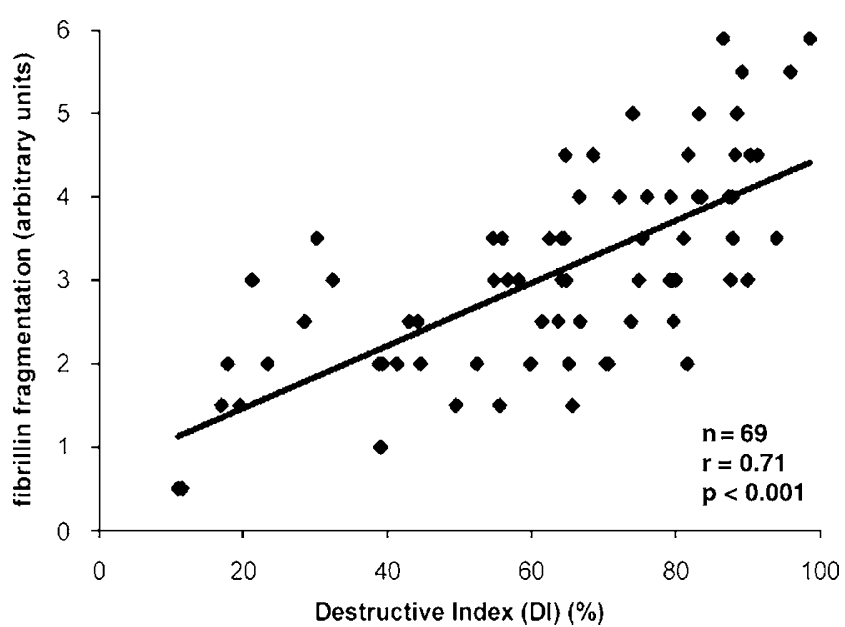

Figure 4 Fibrillin-1 fragmentation as a function of the Destructive Index (DI). By means of an arbitrary scale ranging from no fragmentation (0) to maximal fragmentation (6), fibrillin-1 fragmentation was plotted against the DI. A significant correlation was found between fibrillin-1 fragmentation and DI $(P<0.001)$. The regression coefficient equals 0.71 . Each point represents an individual patient.

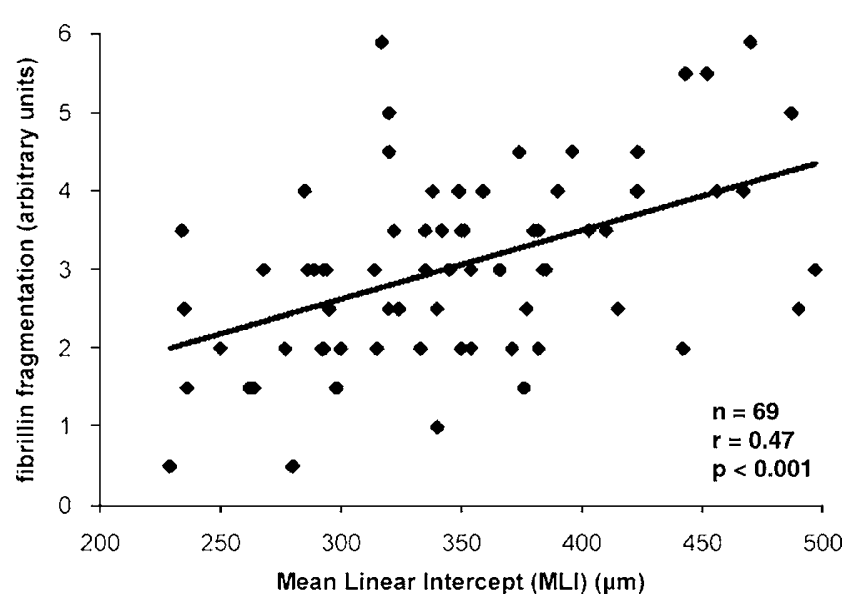

Figure 5 Fibrillin-1 fragmentation as a function of mean linear intercept (MLI). By means of an arbitrary scale ranging from no fragmentation (0) to maximal fragmentation (6), fibrillin-1 fragmentation was plotted against the MLI. A significant correlation was found between fibrillin-1 fragmentation and MLI $(P<0.001)$. The regression coefficient equals 0.47 . Each point represents an individual patient.

the use of these tests to merely establish emphysema is controversial. ${ }^{42-44}$ Besides that, the relationship between lung function data and the morphological assessment of emphysema has been described as poor. ${ }^{45-48}$ Owing to this insensitivity, lung function tests are of limited value to identify the onset of emphysema. Therefore, clinical manifestations of emphysema are only evident in patients with a wide spread and advanced emphysema. ${ }^{46,49-55}$ Indeed, autopsy studies have indicated that one-third of the lung can be affected by emphysema before respiratory function is impaired. ${ }^{56}$ The onset of emphysema is a process that can only be measured

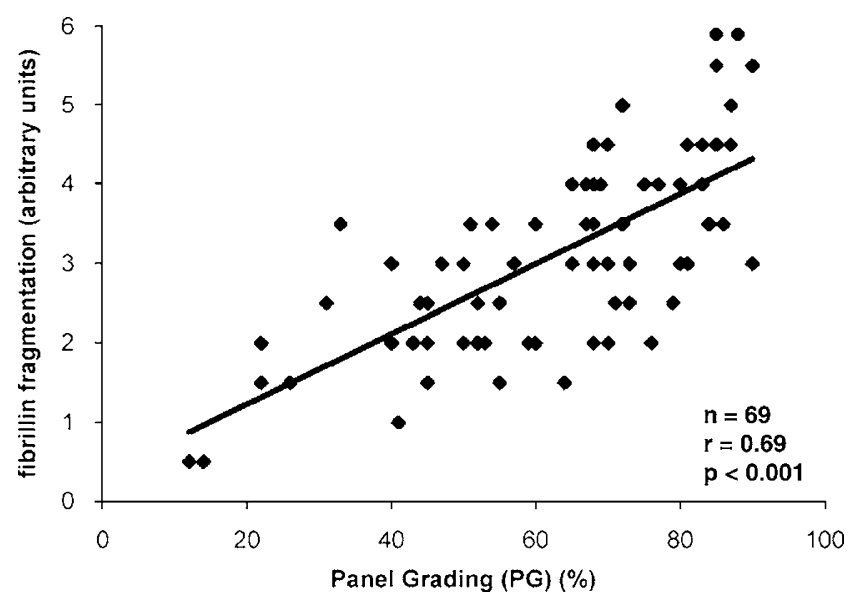

Figure 6 Fibrillin-1 fragmentation as a function of panel grading (PG) value. By means of an arbitrary scale ranging from no fragmentation (0) to maximal fragmentation (6), fibrillin-1 fragmentation was plotted against the PG. A significant correlation was found between fibrillin-1 fragmentation and PG $(P<0.001)$. The regression coefficient equals 0.69. Each point represents an individual patient.

accurately by microscopic measurements. Therefore, this study used lung specimens from patients without clinical manifestations, but with morphological abnormalities indicative of early-onset emphysema. This unique data set allowed us to analyze initiating molecular events in the pathogenesis of emphysema.

Our data suggest that fibrillin-1 is an important player in the onset of adult emphysema. This notion is underlined by the observation that staining for other extracellular matrix molecules (laminin, type I collagen, and type IV collagen) was not aberrant. The hypothesis that fibrillin-1 is a major player in the onset of emphysema is corroborated by other lines of research that have correlated fibrillin-1 with developmental emphysema. Mutated forms of fibrillin-1 are causative for developmental emphysema in mouse models. ${ }^{30,32}$ Tight skin mice, characterized by a tandem duplication of $30-40 \mathrm{~kb}$ in the gene encoding fibrillin- $1,{ }^{31}$ have an abnormal immunostaining for fibrillin- $1{ }^{29}$ Fibroblasts from these mice synthesize and secrete normal as well as oversized fibrillin-1 protein. ${ }^{28,29}$ The resulting abnormal fibrillin-1 assembly results in emphysema that is in many ways similar to that observed in humans. Emphysematous lesions are also observed in another mouse model harboring a targeted deletion of $6 \mathrm{~kb}$ in the fibrillin-1 gene. ${ }^{33}$ As a result, elastic fibers have less tensile strength, resulting in mechanical collapse, overstretching, and fracturing. At such sites, the influx of inflammatory cells is noted. In man, mutations in the fibrillin-1 gene are causative for Marfan syndrome, an autosomal disorder affecting the cardiovascular, skeletal, and ocular system. ${ }^{20,22,24}$ To date, over 500 fibrillin-1 mutations have been identified. ${ }^{57}$ Mutations are found throughout the gene and result in a reduced 

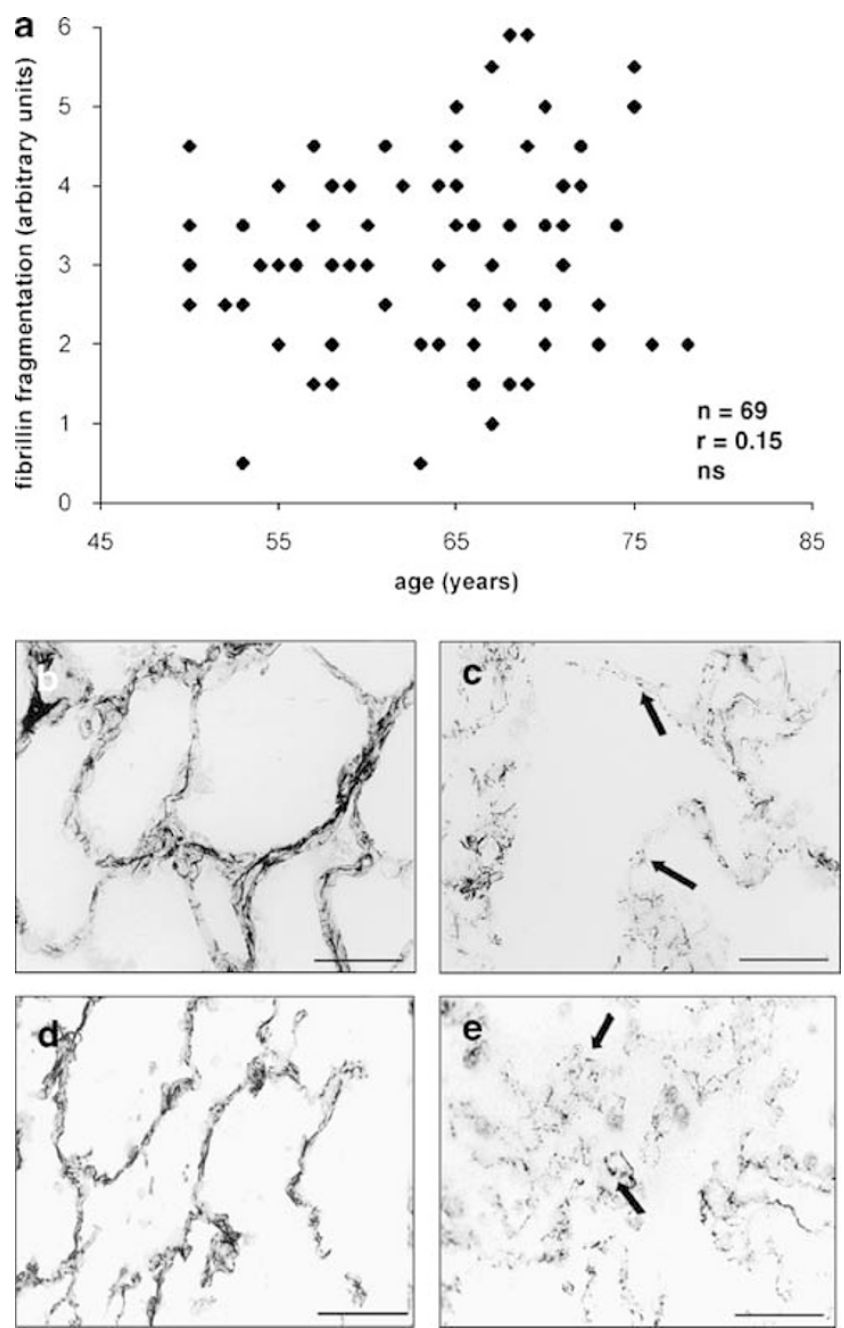

Figure 7 Lack of correlation between fibrillin-1 fragmentation and age. (a) Fibrillin-1 as a function of age. By means of an arbitrary scale ranging from no fragmentation (0) to maximal fragmentation (6), fibrillin-1 fragmentation was plotted against age. No significant correlation was found between fibrillin-1 fragmentation and age. The regression coefficient equals 0.15 . Each point represents an individual patient. (b-e) Fibrillin-1 immunostaining in specimens from patients with similar age, but different DIs. Cryosections derived from a young patient (41 years) with a low DI (11\%) (b) and a young patient (42 years) with a high DI $(70 \%)(\mathbf{c})$ were incubated with an antibody against fibrillin-1. Likewise, cryosections from an older patient (78 years) with a low DI (23\%) (d) and an older patient (68 years) with a high DI $(87 \%)(\mathbf{e})$ were immunostained for fibrillin-1. Bound antibody was visualized with biotinylated anti-mouse IgG followed by DAB incubation. Note the abundant, helical, fibrillin-1 staining in the young patient and older patient with a low DI (a, d) and the small, dot-like fibrillin-1 structures (arrows) in the young patient and older patient with a high DI (b,e). Bar $=50 \mu \mathrm{m}$.

fibrillin-1 synthesis, a delayed secretion, and thus an impaired fibrillin-1 deposition into the matrix. The fragmented fibrillin-1 staining observed in our lung specimens is similar to the fibrillin-1 staining observed in skin specimens from Marfan patients. ${ }^{58,59}$ Strikingly, developmental emphysema has been noticed in a number of Marfan syndrome patients, although studies are scarce. In one study,

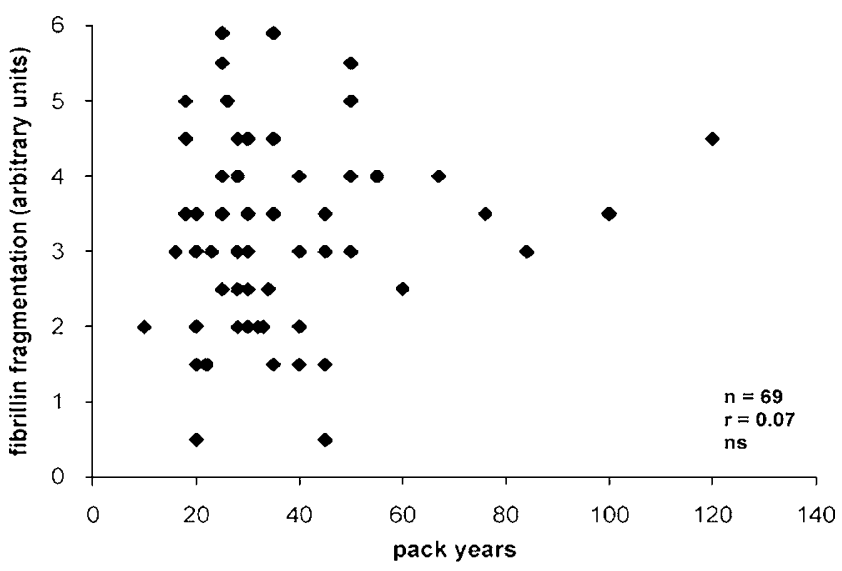

Figure 8 Fibrillin-1 fragmentation as a function of smoking. By means of an arbitrary scale ranging from no fragmentation (0) to maximal fragmentation (6), fibrillin-1 fragmentation was plotted against smoking (expressed in pack years). No significant correlation was found between fibrillin-1 fragmentation and smoking. The regression coefficient equals 0.07. Each point represents an individual patient.

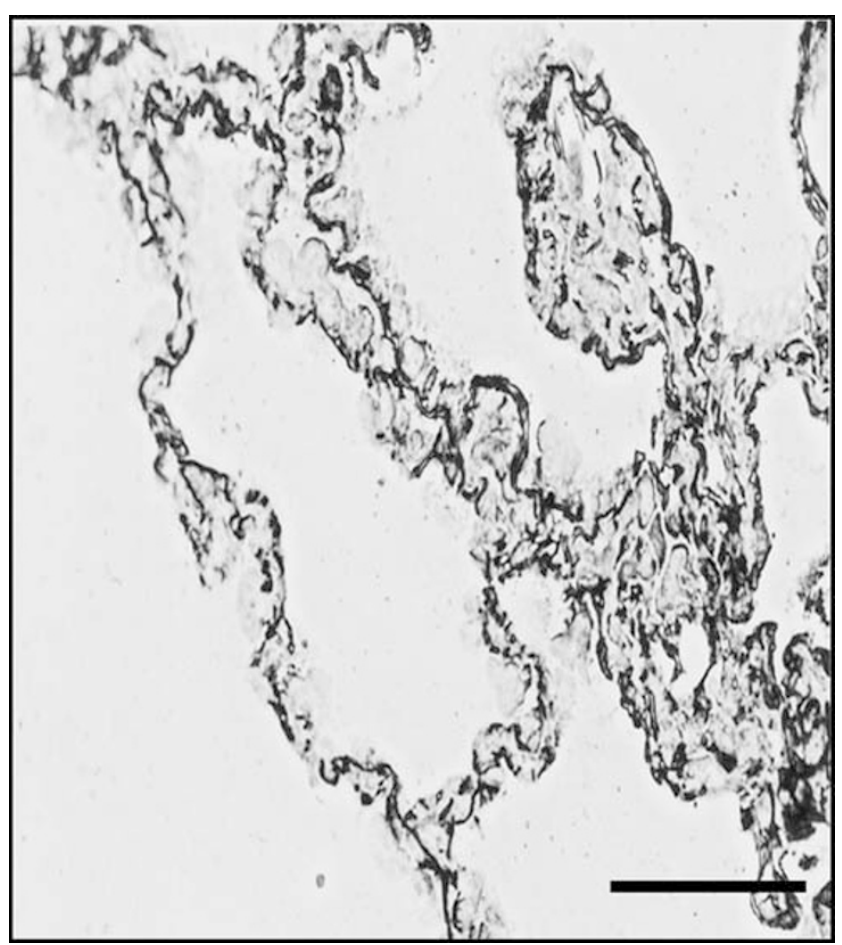

Figure 9 Fibrillin-1 immunostaining in a lung specimen derived from large cell carcinoma. A cryosection from non-emphysematous tissue $(\mathrm{DI}=20 \%, \mathrm{MLI}=264 \mu \mathrm{m}, \mathrm{PG}=22 \%$; age of patient: 57 years, and 40 pack years), affected by large cell carcinoma, was incubated with an antibody against fibrillin-1. The section contains alveolar fibrosis, due to a desmoplastic reaction, and infiltrated cells. Bound antibody was visualized with biotinylated anti-mouse IgG followed by DAB incubation. Note the abundant fibrillin-1 staining, which was present throughout the alveolar septa. $\mathrm{Bar}=50 \mu \mathrm{m}$.

three out of four autopsied cases $(44,23$, and 25 years of age) displayed emphysema on microscopical examination, as indicated by dilatation of 
alveolar spaces and rupture of alveolar walls. Fragmented elastic fibers, with a granular appearance, and microfibrils were noticed. ${ }^{26}$ In another study, four out of four infants with Marfan syndrome had microscopic emphysema similar to that observed in older patients with emphysema but without Marfan syndrome. ${ }^{19}$ In yet another study, four out of four infants with Marfan syndrome had microscopical features of emphysema, with interrupted, fragmented, and clumped fibers that were not observed in 13 control infants. ${ }^{25}$ About $5 \%$ of the Marfan patients develop bullous emphysema, as detected by chest radiography. ${ }^{27}$ In neonatal Marfan syndrome, a severe form of the disease, emphysema, is common. ${ }^{21,23}$ It should be noted that the presence of emphysema in patients with Marfan syndrome may very well be underestimated. Patients are generally not examined for emphysema/COPD. Before the use of $\beta$-blockers and cardiovascular surgery, patients generally died in their late 30s, an age at which clinical emphysema is generally not manifest.

The observation that fibrillin-1 fragmentation is not correlated with smoking behavior or age is intriguing. Smoking is considered the most important risk factor for emphysema, but, for unknown reasons, only $15 \%$ of smokers actually develop clinical emphysema. ${ }^{60}$ This paradox suggests that, besides smoking, another factor must be involved in the susceptibility to emphysema. Is there another risk factor for emphysema besides smoking? Familial aggregation, implying a genetic predisposition, has been observed for emphysema. ${ }^{61-64}$ This suggests that next to environmental causes, genetic influences are of importance for the susceptibility to emphysema. Clinical emphysema would thus result from combined external risk factors and intrinsic host factors. Emphysema has been associated with polymorphisms in genes encoding epoxide hydrolase, ${ }^{65}$ vitamin D-binding protein, ${ }^{6}$ and heme oxygenase. ${ }^{67}$ However, strong associations between these polymorphisms and the elastic recoil properties of the lung are lacking and correlations with protein levels in human lung have not been reported. ${ }^{68,69}$

Our study presents data that correlate fibrillin-1 to the onset of adult emphysema. This, together with the notion that mutations in the fibrillin-1 gene may result in emphysematous lesions in man (Marfan syndrome) as well as mice, makes the fibrillin-1 gene a strong candidate for the predisposition of smokers to emphysema. The following hypothesis may now be put forward: a mutation in the gene encoding fibrillin-1 results in a (moderately) affected fibrillin-1 protein in the lung. Once the lung is challenged, for example, by smoking, the affected fibrillin-1 will lead to defective elastic fibers and to the loss of elasticity, which is the major hallmark of emphysema. Owing to the loss of elastic fibers, breathing will be compromised and clinical emphysema will develop.

\section{Acknowledgement}

We express our gratitude to The Netherlands Asthma Foundation for financial support (NAF project 95.44). The lung specimens were kindly provided by the Department of Lung Diseases, University Lung Center Nijmegen, and the Department of Lung Diseases, Canisius-Wilhelmina Hospital Nijmegen.

\section{Disclosure/conflict of interest}

The authors have declared no conflict of interest.

\section{References}

1 The definition of emphysema. Report of a National Heart, Lung, and Blood Institute, Division of Lung Diseases Workshop. Am Rev Respir Dis 1985;132: 182-185.

2 Gadek JE, Fells GA, Zimmerman RL, et al. Role of connective tissue proteases in the pathogenesis of chronic inflammatory lung disease. Environ Health Perspect 1984;55:297-306.

3 Repine JE, Bast A, Lankhorst I. Oxidative stress in chronic obstructive pulmonary disease. Oxidative Stress Study Group. Am J Respir Crit Care Med 1997;156:341-357.

4 Kielty CM, Sherratt MJ, Shuttleworth CA. Elastic fibres. J Cell Sci 2002;115:2817-2828.

5 Rosenbloom J, Abrams WR, Mecham R. Extracellular matrix 4: the elastic fiber. FASEB J 1993;7:1208-1218.

6 Kielty G, Baldock C, Lee D, et al. Fibrillin: from microfibril assembly to biochemical function. Philos Trans R Soc Lond 2002;357:207-217.

7 Ramirez F, Pereire L. Molecules in focus; the fibrillins. Int J Biochem Cell Biol 1999;31:255-259.

8 Robinson PN, Godfrey M. The molecular genetics of Marfan syndrome and related microfibrillopathies. J Med Genet 2000;37:9-25.

9 Kelleher CM, Silverman EK, Broekelmann T, et al. A functional mutation in the terminal exon of elastin in severe, early-onset chronic obstructive pulmonary disease. Am J Respir Cell Mol Biol 2005;33:355-362.

10 Roark EF, Keene DR, Haudenschild CC, et al. The association of human fibulin-1 with elastic fibers: an immunohistological, ultrastructural, and RNA study. J Histochem Cytochem 1995;43:401-411.

11 Yanagisawa H, Davis E, Starcher B, et al. Fibulin-5 is an elastin-binding protein essential for elastic fiber development in vivo. Nature 2002;415:168-175.

12 Zhang RZ, Pan TC, Zhang ZY, et al. Fibulin-2 (FBLN2): human cDNA sequence, mRNA expression, and mapping of the gene on human and mouse chromosomes. Genomics 1994;22:425-430.

13 Gibson MA, Hughes JL, Fanning JC, et al. The major antigen of elastin-associated microfibrils is a $31-\mathrm{kDa}$ glycoprotein. J Biol Chem 1986;261:11429-11436.

14 Gibson MA, Kumaratilake JS, Cleary EG. The protein components of the 12-nanometer microfibrils of elastic and nonelastic tissues. J Biol Chem 1989;264: 4590-4598.

15 Gibson MA, Hatzinikolas G, Kumaratilake JS, et al. Further characterization of proteins associated with 
elastic fiber microfibrils including the molecular cloning of MAGP-2 (MP25). J Biol Chem 1996;271: 1096-1103.

16 Bressan GM, Daga-Gordini D, Colombatti A, et al. Emilin, a component of elastic fibers preferentially located at the elastin-microfibrils interface. J Cell Biol 1993;121:201-212.

17 Colombatti A, Doliana R, Bot S, et al. The EMILIN protein family. Matrix Biol 2000;19:289-301.

18 Doliana R, Mongiat M, Bucciotti F, et al. EMILIN, a component of the elastic fiber and a new member of the C1q/tumor necrosis factor superfamily of proteins. J Biol Chem 1999;274:16773-16781.

19 Bolande RP, Tucker AS. Pulmonary emphysema and other cardiorespiratory lesions as a part of the Marfan abiotrophy. Pediatrics 1964;33:356-366.

20 Collod-Beroud G, Boileau C. Marfan syndrome in the third Millennium. Eur J Hum Genet 2002;10:673-681.

21 Jacobs AM, Toudjarska I, Racine A, et al. A recurring FBN1 gene mutation in neonatal Marfan syndrome. Arch Pediatr Adolesc Med 2002;156:1081-1085.

22 Maslen CL, Glanville RW. The molecular basis of Marfan syndrome. DNA Cell Biol 1993;12:561-572.

23 Milewicz DM, Duvic M. Severe neonatal Marfan syndrome resulting from a de novo 3-bp insertion into the fibrillin gene on chromosome 15. Am J Hum Genet 1994;54:447-453.

24 Pyeritz RE. The Marfan syndrome and other microfibrillar disorders. In: Royce PM, Steinmann B (eds). Connective Tissue and Its Heritable Disorders. WileyLiss: New York, 2002, pp 585-626.

25 Reye RD, Bale PM. Elastic tissue in pulmonary emphysema in Marfan syndrome. Arch Pathol 1973;96:427-431.

26 Sayers CP, Goltz RW, Mottiaz J. Pulmonary elastic tissue in generalized elastolysis (cutis laxa) and Marfan's syndrome: a light and electron microscopic study. J Invest Dermatol 1975;65:451-457.

27 Wood JR, Bellamy D, Child AH, et al. Pulmonary disease in patients with Marfan syndrome. Thorax 1984;39:780-784.

28 Gayraud B, Keene DR, Sakai LY, et al. New insights into the assembly of extracellular microfibrils from the analysis of the fibrillin 1 mutation in the tight skin mouse. J Cell Biol 2000;150:667-680.

29 Kielty CM, Raghunath M, Siracusa LD, et al. The tight skin mouse: demonstration of mutant fibrillin-1 production and assembly into abnormal microfibrils. J Cell Biol 1998;140:1159-1166.

30 Rossi GA, Hunninghake GW, Gadek JE, et al. Hereditary emphysema in the tight-skin mouse. Evaluation of pathogenesis. Am Rev Respir Dis 1984;129:850-855.

31 Siracusa LD, McGrath R, Ma Q, et al. A tandem duplication within the fibrillin 1 gene is associated with the mouse tight skin mutation. Genome Res 1996;6:300-313.

32 Szapiel SV, Fulmer JD, Hunninghake GW, et al. Hereditary emphysema in the tight-skin (Tsk/+) mouse. Am Rev Respir Dis 1981;123:680-685.

33 Pereira L, Andrikopoulos K, Tian J, et al. Targeting of the gene encoding fibrillin-1 recapitulates the vascular aspect of Marfan syndrome. Nat Genet 1997;17: 218-222.

34 Robbesom AA, Versteeg EM, Veerkamp JH, et al. Morphological quantification of emphysema in small human lung specimens: comparison of methods and relation with clinical data. Mod Pathol 2003;16:1-7.
35 Quanjer PH, Tammeling GJ, Cotes JE, et al. Lung volumes and forced ventilatory flows. Report Working Party Standardization of Lung Function Tests, European Community for Steel and Coal. Official Statement of the European Respiratory Society. Eur Respir J Suppl 1993;16:5-40.

36 van Kuppevelt TH, Robbesom AA, Versteeg EM, et al. Restoration by vacuum inflation of original alveolar dimensions in small human lung specimens. Eur Respir J 2000;15:771-777.

37 Saetta M, Shiner RJ, Angus GE, et al. Destructive index: a measurement of lung parenchymal destruction in smokers. Am Rev Respir Dis 1985;131: 764-769.

38 Dunnill MS. The classification and quantification of emphysema. Proc R Soc Med 1969;62:1024-1027.

39 Nagai A, Yamawaki I, Thurlbeck WM, et al. Assessment of lung parenchymal destruction by using routine histologic tissue sections. Am Rev Respir Dis 1989;139:313-319.

40 Weibel ER. Principles and methods for the morphometric study of the lung and other organs. Lab Invest 1963;12:131-155.

41 Pauwels RA, Buist AS, Ma P, et al. Global strategy for the diagnosis, management, and prevention of chronic obstructive pulmonary disease: National Heart, Lung, and Blood Institute and World Health Organization Global Initiative for Chronic Obstructive Lung Disease (GOLD): executive summary. Respir Care 2001;46: 798-825.

42 Nagai A, West WW, Paul JL, et al. The National Institutes of Health Intermittent Positive-Pressure breathing trial: pathology studies. I. Interrelationship between morphologic lesions. Am Rev Respir Dis 1985;132:937-945.

43 Nagai A, West WW, Thurlbeck WM. The National Institutes of Health Intermittent Positive-Pressure Breathing trial: pathology studies. II. Correlation between morphologic findings, clinical findings, and evidence of expiratory air-flow obstruction. Am Rev Respir Dis 1985;132:946-953.

44 Thurlbeck WM. Overview of the pathology of pulmonary emphysema in the human. Clin Chest Med 1983;4:337-350.

45 Saito K, Cagle P, Berend N, et al. The "destructive index" in nonemphysematous and emphysematous lungs. Morphologic observations and correlation with function. Am Rev Respir Dis 1989;139:308-312.

46 McLean A, Warren PM, Gillooly M, et al. Microscopic and macroscopic measurements of emphysema: relation to carbon monoxide gas transfer. Thorax 1992;47: 144-149.

47 Gevenois PA, De Vuyst P, de Maertelaer V, et al. Comparison of computed density and microscopic morphometry in pulmonary emphysema. Am J Respir Crit Care Med 1996;154:187-192.

48 Gurney JW. Pathophysiology of obstructive airways disease. Radiol Clin North Am 1998;36:15-27.

49 Thurlbeck WM, Angus GE. The relationship between emphysema and chronic bronchitis as assessed morphologically. Am Rev Respir Dis 1963;87:815-819.

50 Sobonya RE, Burrows B. The epidemiology of emphysema. Clin Chest Med 1983;4:351-358.

51 Nicklaus TM, Stowell DW, Christiansen WR, et al. The accuracy of the roentgenologic diagnosis of chronic pulmonary emphysema. Am Rev Respir Dis 1966; 93:889-899. 
52 Knott JM, Christie RV. Radiological diagnosis of emphysema. Lancet 1951;1:881-883.

53 Park SS, Janis M, Shim CS, et al. Relationship of bronchitis and emphysema to altered pulmonary function. Am Rev Respir Dis 1970;102:927-936.

54 Snider GL. Distinguishing among asthma, chronic bronchitis, and emphysema. Chest 1985;87:35S-39S.

55 Gelb AF, Gold WM, Wright RR, et al. Physiologic diagnosis of subclinical emphysema. Am Rev Respir Dis 1973;107:50-63.

56 Uppaluri R, Mitsa T, Sonka M, et al. Quantification of pulmonary emphysema from lung computed tomography images. Am J Respir Crit Care Med 1997;156: 248-254.

57 Collod-Beroud G, Beroud C, Ades L, et al. Marfan Database (third edition): new mutations and new routines for the software. Nucleic Acids Res 1998;26: 229-233.

58 Godfrey M, Olson S, Burgio RG, et al. Unilateral microfibrillar abnormalities in a case of asymmetric Marfan syndrome. Am J Hum Genet 1990;46:661-671.

59 Hollister DW, Godfrey M, Sakai LY, et al. Immunohistologic abnormalities of the microfibrillar-fiber system in the Marfan syndrome. N Engl J Med 1990;323: 152-159.

60 Fletcher C, Peto R. The natural history of chronic airflow obstruction. BMJ 1977;1:1645-1648.

61 Cohen BH, Ball Jr WC, Bias WB, et al. A geneticepidemiologic study of chronic obstructive pulmonary disease. I. Study design and preliminary observations. Johns Hopkins Med J 1975;137:95-104.

62 Hankins D, Drage C, Zamel N, et al. Pulmonary function in identical twins raised apart. Am Rev Respir Dis 1982;125:119-121.

63 Kueppers F, Black LF. Alpha1-antitrypsin and its deficiency. Am Rev Respir Dis 1974;110:176-194.

64 Larson RK, Barman ML, Kueppers F, et al. Genetic and environmental determinants of chronic obstructive pulmonary disease. Ann Intern Med 1970;72:627-632.

65 Smith CA, Harrison DJ. Association between polymorphism in gene for microsomal epoxide hydrolase and susceptibility to emphysema. Lancet 1997;350: 630-633.

66 Horne SL, Cockcroft DW, Dosman JA. Possible protective effect against chronic obstructive airways disease by the GC2 allele. Hum Hered 1990;40:173-176.

67 Yamada N, Yamaya M, Okinaga S, et al. Microsatellite polymorphism in the heme oxygenase-1 gene promoter is associated with susceptibility to emphysema. Am J Hum Genet 2000;66:187-195.

68 Schellenberg D, Pare PD, Weir TD, et al. Vitamin D binding protein variants and the risk of COPD. Am J Respir Crit Care Med 1998;157:957-961.

69 Yim JJ, Park GY, Lee CT, et al. Genetic susceptibility to chronic obstructive pulmonary disease in Koreans: combined analysis of polymorphic genotypes for microsomal epoxide hydrolase and glutathione $S$-transferase M1 and T1. Thorax 2000;55:121-125. 